\title{
The Role of Follicular Fluid Anti-Mullerian Hormone in Success Rate of Intracytoplasmic Sperm Injection
}

Hiathm Ahmed Baha El-Din, Essam Ahmed El Gindy, Ahmed Kotb Ahmed, Osama Ahmed Ibrahim*, Ayman Nady Abdelmegeed Department of Obstetrics and Gynecology, Faculty of Medicine, Minia University, Minya, Egypt

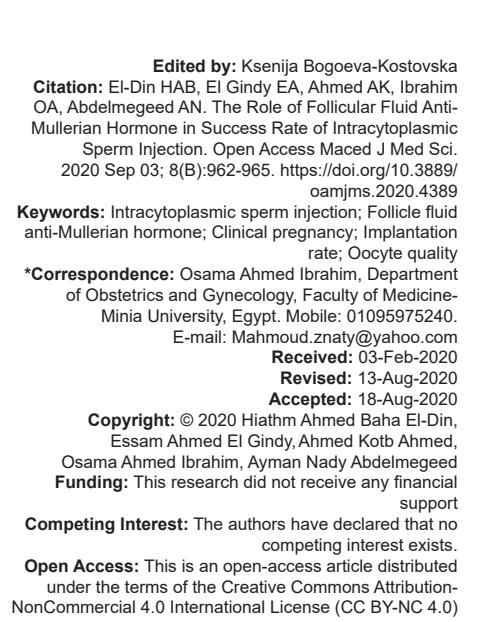

\begin{abstract}
BACKGROUND: The role of anti-Mullerian hormone (AMH) in the ovary is to participate in the regulation of ovarian function, especially in follicle development and selection. It inhibits the initiation of human primordial follicle growth and prevents multiple selection of a dominant follicle by reducing the sensitivity of follicles to follicle stimulating hormone.

MATERIALS AND METHODS: In this prospective clinical trial, outcomes were followed in 60 women undergoing cycles of in vitro fertilization (IVF)/intracytoplasmic sperm injection (ICSI) within EI-Minia University Hospital. AMH concentration was estimated in pooled follicle fluid (FF) on day of oocyte pickup. Cycles were sorted into low and high groups according to median $\left(50^{\text {th }}\right.$ centile) values of measurement. The fertilization rate (FR), implantation rate, blastocyst development, embryo quality, chemical pregnancy, clinical pregnancy, and ongoing pregnancy after ICSI were counted as the main outcomes.

RESULTS: Low FF AMH group shows significantly higher percentage of top-quality oocytes (67.1 \pm 24.3 vs $49.6 \pm 30.3 \%, p=0.014)$, FR $(83.9 \pm 20.9$ vs. $72.4 \pm 21.4 \%, p=0.021)$, clinical pregnancy $(57.57$ vs. $16.67 \%$, $p>0.0001)$, and embryo implantation rates $(57.7$ vs. $16.7 \%, p=0.001)$ compared to high FF AMH group. FF AMH shares an inverse correlation with FF E2 (Pearson $r=-0.409, \mathrm{p}<0.001$ ) and clinical pregnancy (Pearson $r=-0.618$, $\mathrm{p}<0.001)$. Threshold value of FF AMH for pregnancy is $>1.75 \mathrm{ng} / \mathrm{mg}$ protein.
\end{abstract}

CONCLUSION: FF AMH is a plausible specific indicator of functional viability and quality of oocyte in IVF cycles.

\section{Introduction}

Anti-Mullerian hormone $(\mathrm{AMH})$, also referred to as Mullerian inhibiting substance, may be a dimeric glycoprotein member of the reworking growth factor- $\beta$ family. $\mathrm{AMH}$ is secreted by granulosa cells within preantral and early antral follicles, $<4 \mathrm{~mm}$ in diameter. Its secretion decreases because the antral follicles begin to grow and stops when the follicles are larger $8 \mathrm{~mm}$ in diameter or when atresia occurs [1]. A previous study has showed that the performance of $\mathrm{AMH}$ as a predictor of poor ovarian response was very almost like that achieved with antral follicle counts (AFCs) [2]. However, AFC was tested within the early stage of the cycle and was evaluated using ultrasound [3].

Thus, the accuracy and stability of AFC testing are inferior thereto achieved with serum AMH. The previous studies have found associations between AMHs (including serum $\mathrm{AMH}$ and follicle fluid [FF] $\mathrm{AMH})$, fertilization rate (FR), blastocyst development, embryo quality, pregnancy outcome, and birth rate live birth rates. Some studies showed that prime serum AMH levels on day 3 were correlated with high numbers of mature oocytes, leading to more embryos and ultimately a better clinical pregnancy rate [4]. Other workers found no associations between basal serum $\mathrm{AMH}$ levels and embryo quality [5]. An association has also been found between FF AMH (FF AMH) levels and therefore the quality of embryos in patients with polycystic ovary syndrome (PCOS) [6]. However, during this study population, there was no correlation between FF AMH and therefore the degree of maturation of retrieved oocytes or the success of fertilization.

The aim of this work is to know the predictive value of $\mathrm{AMH}$ on $\mathrm{FR}$, implantation rate, blastocyst development, embryo quality, chemical pregnancy, clinical pregnancy, and ongoing pregnancy after intracytoplasmic sperm injection (ICSI).

\section{Materials and Methods}

This quasi-experimental study was conducted in the Department of Obstetrics and Gynecology, EI-Minia Infertility Center Faculty of Medicine, El-Minia University and two private centers during the period 
from June 2016 to June 2018 after being approved by the Department of Ethical Committee. The study population included 60 women who had their first cycles of ICSI treatment.

\section{Inclusion criteria}

The women with age $\leq 38$ years, the body mass indexes (BMls between 18 and $29 \mathrm{~kg} / \mathrm{m}^{2}$ ), day 3 serum follicle-stimulating hormone (FSH) levels <12 IU/L, the women with a history of regular, ovulatory menstrual cycles (every 24-35 days), and the women with no previous history of ovarian surgery were included in the study.

\section{Exclusion criteria}

Women with ovarian cyst ( $>3 \mathrm{~cm}$ in diameter), women with PCOS, women with endometriosis, and women with a history of ovarian surgery or endocrine disorders were excluded from the study.

\section{Methods}

- $\quad$ All patients were subjected on day 3 of the menstrual cycle and before treatment, blood samples for assay of $\mathrm{AMH}, \mathrm{FSH}, \mathrm{E} 2$, and luteinizing hormone $(\mathrm{LH})$ were collected by venipuncture

- $\quad$ Ultrasound scanning with a $6.5 \mathrm{MHz}$ transvaginal probe was used to count the number of antral follicles in each ovary that had a mean diameter of 3-10 mm

- $\quad \mathrm{AMH}$ was measured using the immunotech enzyme immune assay kit consistent with the handbook. On the day of ovum pick-up, under transvaginal ultrasound guidance, fluid from 3 to 5 dominant follicles was gently and thoroughly aspirated employing a $10 \mathrm{~mL}$ syringe. The fluid was maintained at $37^{\circ} \mathrm{C}$ until the oocyte was found and isolated

- $\quad$ The level of $\mathrm{AMH}$ in FF was measured as described above

- All patients received standard ovarian stimulation protocol with recombinant $\mathrm{FSH}$ under pituitary suppression with a $\mathrm{GnRH}$ agonist

- $\quad$ Briefly, the GnRH agonist (Decapeptyl, $3.75 \mathrm{mg}$ Ferring, Kiel, Germany) was administered subcutaneously in the mid-luteal phase of the previous menstrual cycle

- $\quad$ Stimulation commenced 2 weeks later, when the circulating E2 level was $<150 \mathrm{pmol} / \mathrm{L}$, the thickness of endometrium was $<5 \mathrm{~mm}$, serum $\mathrm{LH}$ was $<5 \mathrm{IU} / \mathrm{L}$, and a vaginal ultrasonographic scan showed an absence of follicles more than $10 \mathrm{~mm}$ in diameter (HCG) administration are the presence of 3 or

more follicles $\geq 17-18 \mathrm{~mm}$ in diameter with a consistent rise in serum estradiol concentration Oocyte aspiration was performed using vaginal ultrasound, 34-36 h after HCG injection

Egg quality: Metaphase II oocyte collected from the patient varying in qualities, both nuclear and cytoplasmic maturation have to be completed in a coordinate mode to ensure optimal condition for subsequent fertilization. Disturbances of these processes may result in different morphological abnormalities, depending on whether nuclear or cytoplasmic maturation has been affected

- $\quad$ ICSI was performed using standard procedures and the embryos were transferred 2 or 3 days later. The luteal phase was supported with $40 \mathrm{mg}$ progesterone administration by daily injection

- A pregnancy test was carried out on day 14 after embryo transfer

After 2 weeks, a transvaginal ultrasound was performed to confirm pregnancy

Study endpoints were FR, the good quality embryos, clinical pregnancy, and biochemical pregnancy

- $\quad$ Then, follow-up of the pregnant women by serial ultrasound was done.

\section{Ethical consent}

The nature of the study was clearly explained to each patient. An informed written consent was obtained. Furthermore, an approval from the local committee was taken.

\section{Results}

Results were analyzed using SPSS (ver. 25.0; IBM, Chicago, IL, USA). Quantitative data were displayed in the form of mean \pm standard deviation (SD). Qualitative data were demonstrated through figures of frequency and percentage. Table 1: This table showed that age, BMI, baseline $A M H$, and E2d HCG showed statistical insignificant difference between both groups, while FF E2 was significantly higher among low than high group $(p=0.001)$. Table 2 : This table showed significantly higher rates of fertilization, more number of

Table 1: Hormone data in low versus high FF AMH groups

\begin{tabular}{|c|c|c|c|c|}
\hline Variables & $\begin{array}{l}\text { Low FF AMH }(\leq 1.720 \\
n g / m g \text { protein })(n=30)\end{array}$ & $\begin{array}{l}\text { High FF AMH }(>1.720 \\
n g / m g \text { protein })(n=30)\end{array}$ & $\begin{array}{l}\text { Test } \\
\text { value }\end{array}$ & $\mathrm{p}$-value \\
\hline Age (years) & $32.6 \pm 1.09$ & $32.5 \pm 1.04$ & 0.482 & $0.631^{1}$ \\
\hline BMI $\left(\mathrm{kg} / \mathrm{m}^{2}\right)$ & $27.6 \pm 1.4$ & $28.03 \pm 1.4$ & 1.196 & $0.231^{1}$ \\
\hline Baseline $(d 3)$ serum & $1.73 \pm 0.21$ & $2.24 \pm 0.30$ & 2.120 & $0.195^{1}$ \\
\hline AMH $(\mathrm{ng} / \mathrm{mL})$ & & & & \\
\hline E2 d hCG $(\mathrm{pg} / \mathrm{mL})$ & $1221.9 \pm 21.11$ & $1185.3 \pm 17.8$ & 0.921 & $0.420^{1}$ \\
\hline FF E2 (pg/mL) & $262628.5 \pm 155320$ & $164853.8 \pm 52411$ & 29.04 & $0.001^{* 1}$ \\
\hline
\end{tabular}


Table 2: Embryology data in low versus high FF AMH groups

\begin{tabular}{|c|c|c|c|c|}
\hline Variables & $\begin{array}{l}\text { Low FF AMH }(\leq 1.720 \\
\mathrm{ng} / \mathrm{mg} \text { protein })(\mathrm{n}=30)\end{array}$ & $\begin{array}{l}\text { High FF AMH }(>1.720 \\
\mathrm{ng} / \mathrm{mg} \text { protein) }(\mathrm{n}=30)\end{array}$ & $\begin{array}{l}\text { Test } \\
\text { value }\end{array}$ & $p$-value \\
\hline $\begin{array}{l}\text { No. of oocytes } \\
\text { retrieved }\end{array}$ & 416 & 402 & 1.23 & $0.731^{1}$ \\
\hline $\begin{array}{l}\text { Topquality oocytes } \\
(\%)\end{array}$ & $67.1 \pm 24.3$ & $49.6 \pm 30.3$ & 23.81 & $0.014^{* 1}$ \\
\hline Fertilization rate $(\%)$ & $83.9 \pm 20.9$ & $72.4 \pm 21.4$ & 18.56 & $0.021^{\star 1}$ \\
\hline $\begin{array}{l}\text { Total no. of embryos } \\
\text { transferred (mean) }\end{array}$ & $140(1.98 \pm 0.87)$ & $159(2.29 \pm 0.91)$ & 31.34 & $0.016^{* 1}$ \\
\hline $\begin{array}{l}\text { No. of clinical } \\
\text { pregnancies (\%) }\end{array}$ & $17(56.7)$ & $5(16.7)$ & 10.34 & $0.001^{*^{2}}$ \\
\hline $\begin{array}{l}\text { No. of twin } \\
\text { pregnancies (\%) }\end{array}$ & $3(10)$ & $2(6.7)$ & 0.220 & $0.884^{3}$ \\
\hline $\begin{array}{l}\text { Embryo } \\
\text { implantation rate } \\
(\%)\end{array}$ & $10(33.3)$ & $5(16.7)$ & 17.89 & $<0.001^{* 2}$ \\
\hline
\end{tabular}

AHM: Anti-Mullerian hormone, FF: Follicle fluid, BMI: Body mass index.

top-quality oocytes, and higher clinical pregnancy and embryo implantation rates than high FF $\mathrm{AMH}$ group. However, the twin pregnancy rates were comparable and did not differ significantly between the two groups. Figure 1: This figure showed that clinical pregnancy had significant indirect correlations with $\mathrm{AMH}$. Figure 2: ROC curve showed that $A M H$ had $73.1 \%$ sensitivity and $85.3 \%$ specificity for predication of clinical pregnancy.

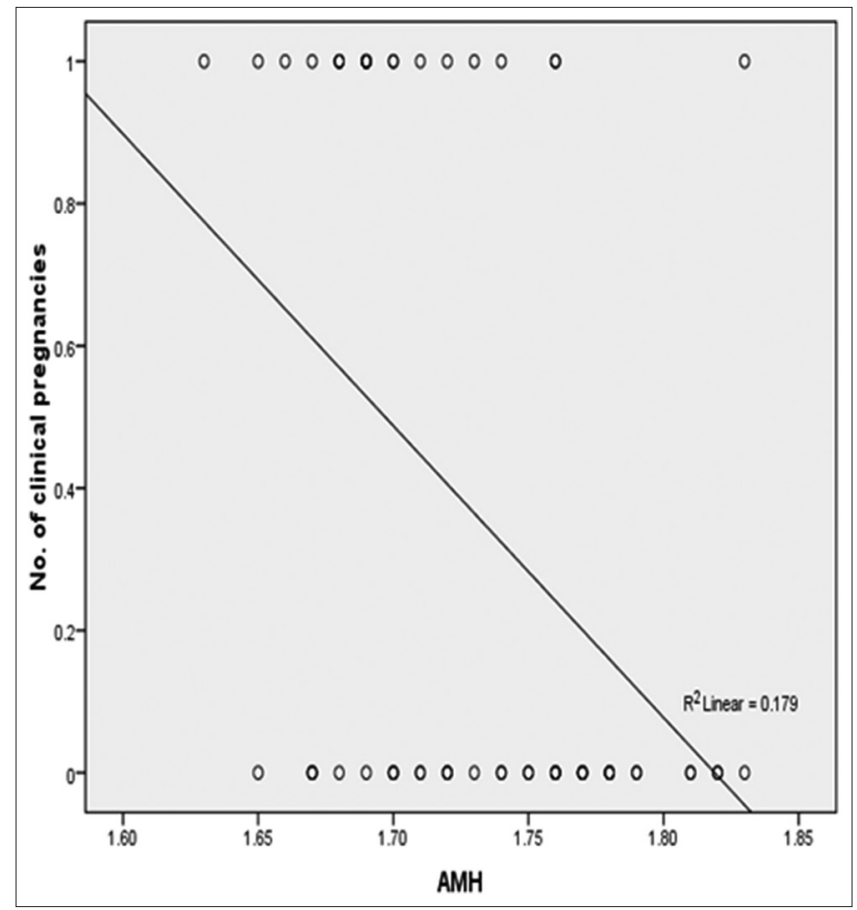

Figure 1: Correlation clinical pregnancy and anti-Mullerian hormone

\section{Discussion}

The role of $\mathrm{AMH}$ within the ovary is to participate within the regulation of ovarian function, especially in follicle development and selection. It inhibits the initiation of human primordial follicle growth and prevents multiple selection of a dominant follicle by reducing the sensitivity of follicles to FSH [7]. Several reports suggest that AMH could be a far better predictor of ovarian responses to controlled ovarian hyperstimulation than traditional parameters such as age, FSH, estradiol (E2), and inhibin B (INHB) [8]. Our results, completely conform to and are in conjunction with earlier reports of a progressive decline in $\mathrm{AMH}$ levels during ovarian stimulation, hence confirming the decreased ability of maturing follicles to supply $\mathrm{AMH}$ [9].

Similar to Mehta et al. [10] study in which FF AMH shares an inverse correlation with FF E2 (Pearson $r=-0.43, r^{2}=0.18$ ) and clinical pregnancy (Pearson $r=-0.46, r^{2}=0.21$ ). Another study administered in monofollicular fluid (FF obtained from each individual follicle) of stimulated cycles by Takahashi et al. [11] reported correlation of upper FF $\mathrm{AMH}$ levels with higher rates of fertilization. However, they might not associate it with pregnancy outcome. Moreover, their study involved comparison of FF $\mathrm{AMH}$ between two broad groups, namely, fertilization success versus fertilization failure. Wunder et al. [12] correlated higher $\mathrm{FF} A M H$ with reproductive outcome in in vitro fertilization (IVF)-ICSI cycles. Some other observe done using Fanchin et al. [13] in monodominant follicles (single lead follicle) of unstimulated cycles, mentioned correlation of FF AMH with implantation rates, and pregnancy outcome but not with fertilization costs. (have a look at, Aflatoonian et al. [14] correlated FF AMH with fertilization and embryo excellent). Concerning $\mathrm{AMH}$ validity, our take a look at consequences determined that $\mathrm{AMH}>1.75$ $\mathrm{ng} / \mathrm{mg}$ had $73.1 \%$ sensitivity and $85.3 \%$ specificity for predication of medical being pregnant.

Furthermore, Mehta et al. [10] have a look at located that $\mathrm{AMH}>1.75 \mathrm{ng} / \mathrm{mg}$ had $80 \%$ sensitivity and $63.1 \%$ specificity for predication of medical being pregnant. Regarding bad reaction, the $\mathrm{AMH}$ cutoff price is $1.26 \mathrm{ng} / \mathrm{mL}$ with a sensitivity of $72.0 \%$ and a specificity of $86.4 \%$. Patients with $\mathrm{AMH}$ underneath

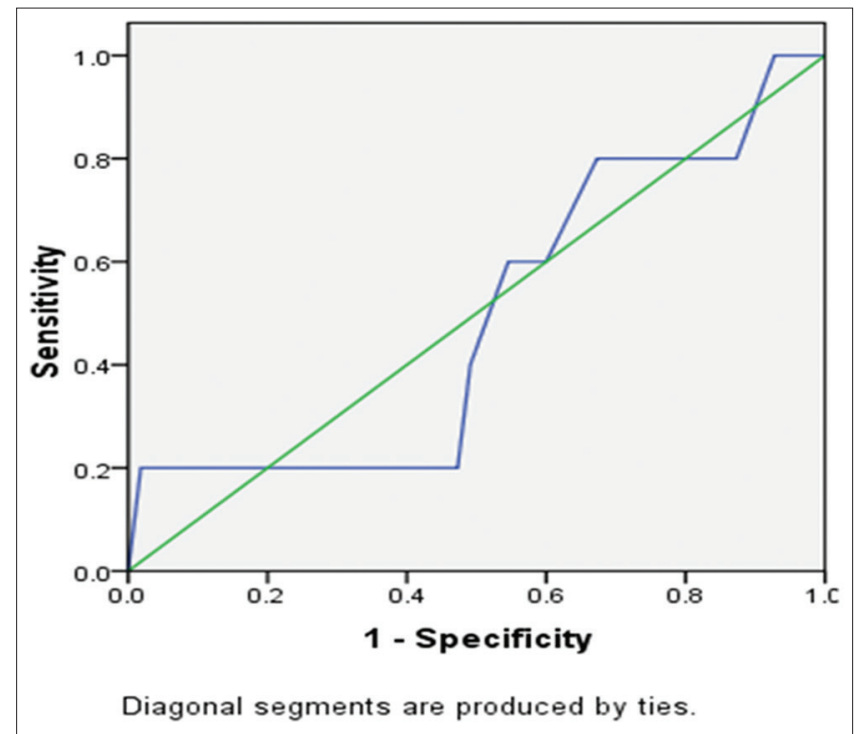

Figure 2: Receiver operating characteristic curve for anti-Mullerian hormone 
this threshold have to be knowledgeable earlier in their fantastically low opportunity of reaching being pregnant because of a substantially higher rate of no available embryos (36.9 vs. $7.3 \%, p<0.001)$. Nevertheless, it must now not be utilized in isolation as the criterion for withholding fertility treatment [15]. A major strength of the current study stems from its prospective and randomized design.

\section{Conclusion}

Our study demonstrates that FF AMH is an adequate predictor of clinical pregnancy after ICSI. Further studies are urgently needed to investigate the efficiency, safety, and cost-effectiveness of individualized gonadotropin dosing based on the $\mathrm{AMH}$ level before IVF.

\section{References}

1. Durlinger AL, Gruijters MJ, Kramer $P$, Karels $B$, Ingraham HA, Nachtigal MW, et al. Anti-Mullerian hormone inhibits initiation of primordial follicle growth in the mouse ovary. Endocrinology. 2002;143(3):1076-84. https://doi.org/10.1210/endo.143.3.8691 PMid: 11861535

2. Broer SL, Mol BW, Hendriks D, Broekmans FJ. The role of antimullerianhormoneinprediction ofoutcomeafterIVF:comparison with the antral follicle count. Fertil Steril. 2009;91(3):705-14. https://doi.org/10.1016/j.fertnstert.2007.12.013

PMid:18321493

3. Broekmans FJ, Kwee J, Hendriks DJ, Mol BW, Lambalk CB. A systematic review of tests predicting ovarian reserve and IVF outcome. Hum Reprod Update. 2006;12(6):685-718. https://doi. org/10.1093/humupd/dml034

PMid:16891297

4. Lekamge DN, Barry M, Kolo M, Lane M, Gilchrist RB, Tremellen KP. Anti-mullerian hormone as a predictor of IVF outcome. Reprod Biomed Online. 2007;14(5):602-10. https:// doi.org/10.1016/s1472-6483(10)61053-x

PMid:17509203

5. Fong SL, Baart EB, Martini E, Schipper I, Visser JA, Themmen AP, et al. Anti-mullerian hormone: A marker for oocyte quantity, oocyte quality and embryo quality? Reprod Biomed Online. 2008;16(5):664-70. https://doi.org/10.1016/ s1472-6483(10)60480-4

PMid: 18492370

6. Mashiach R, Amit A, Hasson J, Amzalzg S, Almog B,
Ben-Yosef D, et al. Follicular fluid levels of anti-mullerian hormone as a predictor of oocyte maturation, fertilization rate, and embryonic development in patients with polycystic ovary syndrome. Fertil Steril. 2010;93(7):2299-302. https://doi. org/10.1016/j.fertnstert.2009.01.125

\section{PMid:19261276}

7. Hamdine O, Eijkemans MJ, Lentjes EW, Torrance HL, Macklon NS, Fauser BC, et al. Ovarian response prediction in $\mathrm{GnRH}$ antagonist treatment for IVF using anti-Mullerian hormone. Hum Reprod. 2015;30(1):170-8. https://doi.org/10.1093/humrep/deu266 PMid:25355590

8. Massin N. New stimulation regimens: Endogenous and exogenous progesterone use to block the LH surge during ovarian stimulation for IVF. Hum Reprod Update. 2017;23(2):211-20. https://doi.org/10.1093/humupd/dmw047 PMid:28062551

9. Bakas P, Boutas I, Creatsa M, Vlahos N, Gregoriou O, Creatsas G, et al. Can anti-mullerian hormone (AMH) predict the outcome of intrauterine insemination with controlled ovarian stimulation? Gynecol Endocrinol. 2015;31(10):765-8. https://doi.org/10.3109/0 9513590.2015.1025381

PMid:26288100

10. Mehta BN, Chimote MN, Chimote NN, Nath NM, Chimote NM. Follicular-fluid anti-mullerian hormone (FF AMH) is a plausible biochemical indicator of functional viability of oocyte in conventional in vitro fertilization (IVF) cycles. J Hum Reprod Sci. 2013;6(2):99-105. https://doi.org/10.4103/0974-1208.117168 PMid:24082650

11. Takahashi C, Fujito A, Kazuka M, Sugiyama R, Ito H, Isaka K. Anti-müllerian hormone substance from follicular fluid is positively associated with success in oocyte fertilization during in vitro fertilization. Fertil Steril. 2008;89(3):586-91. https://doi. org/10.1016/j.fertnstert.2007.03.080

PMid:17543956

12. Wunder DM, Guibourdenche J, Birkhäuser MH, Bersinger NA Anti-müllerian hormone and inhibin $B$ as predictors of pregnancy after treatment by in vitro fertilization/intracytoplasmic sperm injection. Fertil Steril. 2008;90(6):2203-10. https://doi. org/10.1016/j.fertnstert.2007.10.078

PMid: 18291376

13. Fanchin R, Lozano DH, Frydman N, Gougeon A, di Clemente N, Frydman $\mathrm{R}$, et al. Anti-mullerian hormone concentrations in the follicular fluid of the preovulatory follicle are predictive of the implantation potential of the ensuing embryo obtained by in vitro fertilization. J Clin Endocrinol Metab. 2007;92(5):1796-802. https://doi.org/10.1210/jc.2006-1053

PMid:17327387

14. Aflatoonian A, Mashayekhy M, Mohamadian F, Moghaddam FM. The correlation between follicular fluid anti-mullerian hormone levels and fertilization and embryo quality in ART cycles. Iran J Reprod Med. 2010;8:157-60.

15. Seckin B, Aytekin T, Omer HY. The role of anti-müllerian hormone in prediction of pregnancy in young and older women with unexplained infertility undergoing intrauterine insemination. J Chin Med Assoc. 2019;82(4):300-4. https://doi.org/10.1097/ jcma.0000000000000023

PMid:30946209 